\title{
Solitary Endobronchial Anaplastic Large Cell Lymphoma Revealed by Atelectasis: About a Pediatric Observation
}

\author{
Faten Fedhila $^{{ }^{*}}$, Salma Moalla ${ }^{1}$, Samar Rhayem ${ }^{1}$, Elhem Jbebli ${ }^{1}$, Raoudha Doghri ${ }^{2}$, \\ Wiem Khomsi Douira ${ }^{3}$, Monia Khemiri ${ }^{1}$ \\ ${ }^{1}$ Department of pediatric A, Bechir Hamza Children Hospital, Tunis-el Manar, Tunisia \\ ${ }^{2}$ Department of Pathology, Salah Azaiez Institut, University el Manar, Tunis, Tunisia \\ ${ }^{3}$ Department of Pediatric Radiology, Bechir Hamza Children Hospital, Tunis-el Manar, Tunisia
}

*Corresponding author: Faten Fedhila Ben Ayed, MD, Department of Pediatric Oncologic Unit, Bechir Hamza Children's Hospital of Tunis, Bab Saadoun place, 1007, Tunis Jabbari 2083, Tunisia; E-mail: faten.fedhila@yahoo.fr

\begin{abstract}
Endobronchial involvement by anaplastic large cell lymphoma in child is uncommon. We report a case of primary endobronchial isolated anaplastic lymphoma in a 13-year-old girl admitted for cough and dyspnea. Chest X-ray showed complete atelectasis of the right hemithorax. Chest Computed Tomography $(\mathrm{CT})$ revealed a mass occluding the right mainstem bronchus. The fibro bronchoscopy showed polypoid lesion at the right bronchus and pathologic examination concluded to an anaplastic T lymphoma ALK+. Chemotherapy according to ALCL 99 resulted in rapid and complete regression of the tumor. No evidence of local or distant recurrence was reported after 2 years of follow-up.
\end{abstract}

Keywords: Anaplastic lymphoma; Endobronchial; Atelectasis; Child

\section{Introduction}

Anaplastic Large Cell Lymphoma (ALCL) is a CD30+ mature cell lymphoma more often seen in the first three decades of life. It represents 10 to $15 \%$ of all pediatric non-Hodgkin's lymphomas and can affect skin, bone marrow, soft tissue, pelvis, central nervous system, bone, gastrointestinal tract, lung, pleura, breast, chest wall, retro peritoneum, or spleen ${ }^{[1]}$. ALCL involving the lung are commonly due to disseminated disease ${ }^{[2]}$. Primary isolated endobronchial ALCL in the pediatric population is exceedingly rare and very few cases have been reported in the published English literature ${ }^{[2]}$. We report the case of a 13-yearold girl with primary isolated endobronchial ALCL.

\section{Case Report}

13-years-old girl was referred to our hospital with a 1-month history of cough, chest pain, progressive breathlessness and fever. Clinical examination revealed absent breath sounds over her right hemithorax. The patient's vital signs were normal (temperature $=37.2^{\circ} \mathrm{C}$; pulse rate $=78 / \mathrm{min}$; respiratory frequency $=42 / \mathrm{min}$, oxygen saturation as measured by pulse oximetry $=96 \%$ on room air). There was neither lymphadenopathy nor organomegaly. Results of blood tests including count blood cells and biochemistry were within normal limits and particularly LDH rate was normal (173UI/l).
A chest X-ray film revealed atelectasis of the right lung with a complete whiteout of the right hemi thorax and a shift of the mediastinum to the left side [Figure 1]. The thoracic tomography revealed a mass occluding the right main stem bronchus [Figure 2]. No lymphadenopathy was evident in other parts of mediastinum and pulmonary parenchyma was clear on this exam. Fibre-optic bronchoscopy revealed a fleshy tumor arising from the right upper lobe bronchus with complete occlusion of the right main bronchus. Needle aspiration showed a tumoral hemorrhagic bud. Endobronchial biopsy of the mass revealed a tumoral proliferation made of uniform neoplastic cells with round cores and irregular outlines. We also note a polymorph granuloma made of lymphocytes, polynuclear neutrophils and eosinophils. On immunochemistry, tumor cells were strongly

\section{Received date: October 28, 2017 \\ Accepted date: March 6, 2018 \\ Published date: March 13, 2018}

Citation: Fedhila Ben Ayed, F., et al. Solitary Endobronchial Anaplastic Large Cell Lymphoma Revealed by Atelectasis: About a Pediatric Observation. (2018) Int J Cancer Oncol 5(1): 13- 15 .

Copyright: (C) 2018 Fedhila Ben Ayed, F. This is an Open access article distributed under the terms of Creative Commons Attribution 4.0 International License. 
Citation: Fedhila Ben Ayed, F., et al. Solitary Endobronchial Anaplastic Large Cell Lymphoma Revealed by Atelectasis: About a Pediatric Observation. (2018) Int J Cancer Oncol 5(1): .

positive to CD5, CD30, Epithelial Membrane Antigen (EMA), granzyme, Anaplastic Lymphoma Receptor Tyrosine Kinase (ALK), with cytoplasmic and nuclear positivity. Tumor cells were negative for cytokeratin and CD20. The pathological exam was consistent with the diagnosis of anaplastic non-Hodgkin lymphoma.

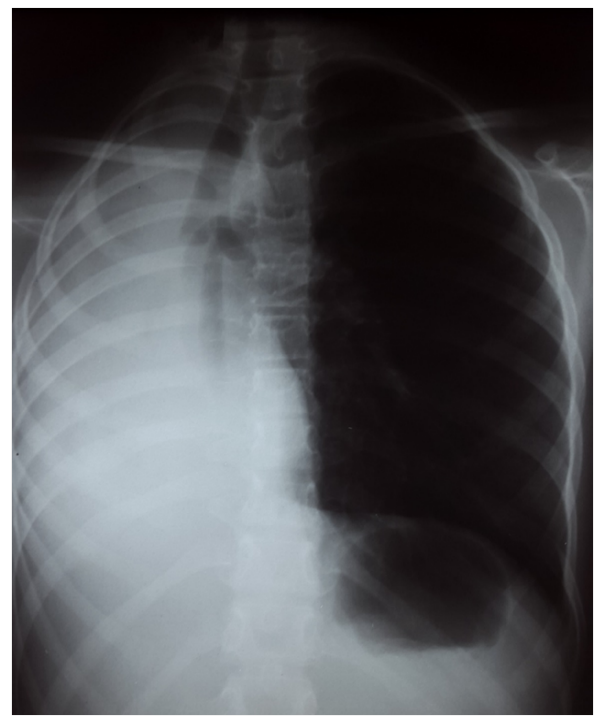

Figure 1: Chest X-ray: Atelectasis of the right lung.

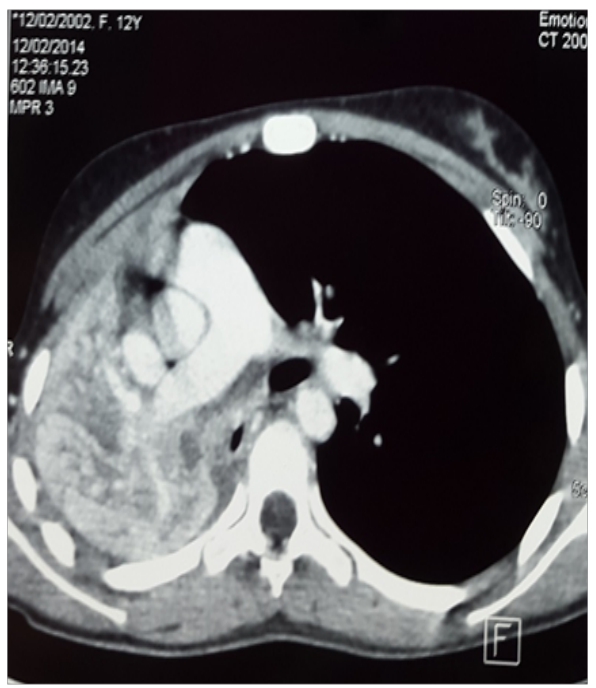

Figure 2: Thoracic Tomography: Tissular mass occluding the right mainstem bronchus.

A detailed staging work-up was undertaken. The bone scan, the medullar aspiration, the lumbar puncture and the abdominal ultrasound did not reveal any metastases or extra thoracic involvement.

She was assigned to the standard risk group proposed by ALCL99, the international multicenter study for pediatric ALCL. The first course of chemotherapy resulted in rapid good response, with disappearance of fever and dyspnea. She received totally six courses of chemotherapy every 21 days. Chest $x$-ray made after four courses revealed a satisfactory response with resolution of the collapses [Figure 3]. At the end of chemotherapy, there was a good response with persistence of a little mass on the upper right lobe of lung $(12 * 14 * 9 \mathrm{~mm})$ on the thoracic tomography [Figure 4]. A fibre-optic bronchoscopy was performed and showed an obstruction of the ventral and dorsal segment of the upper lobe by a white necrotic formation. The liquid aspiration and the biopsy of this formation did not show any tumoral cells.

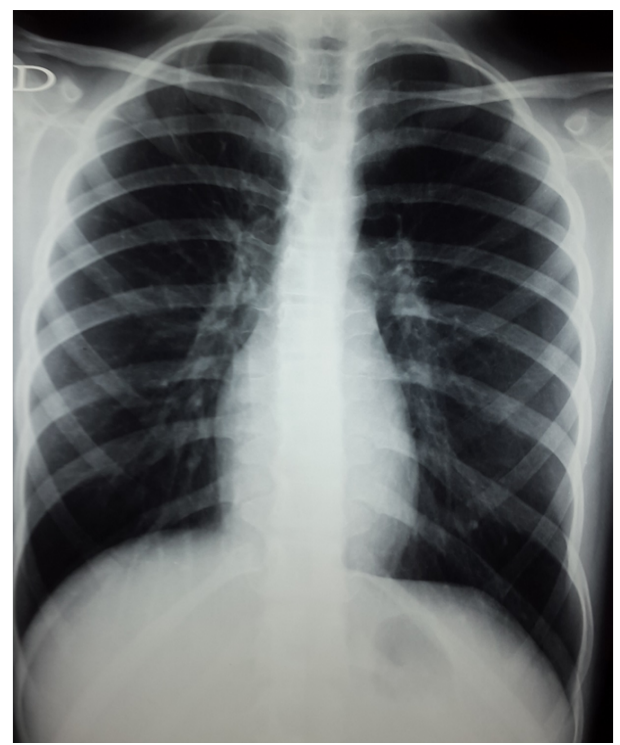

Figure 3: Chest $X$-ray: Normal Chest $X$ ray at the end of treatment.

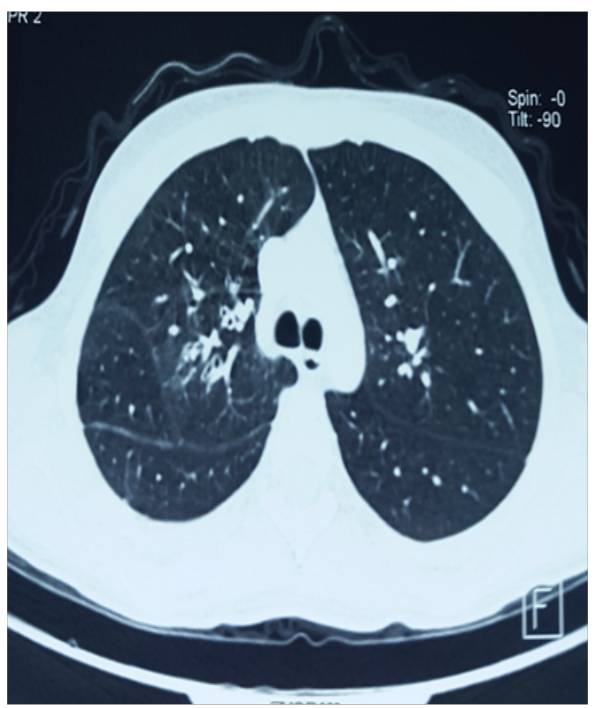

Figure 4: Chest Tomography at the end of treatment: good response with persistence of a little mass on the upper right lobe of lung.

After 2 years on follow-up, she was in complete remission without any evidence of $\mathrm{tu} \neg$ mor recurrence on imaging and bronchoscopy.

\section{Discussion}

Dawe first described a case of endobronchial non-Hodgkin's lymphoma in $1955^{[3]}$. Since this time, only isolated cases have been reported ${ }^{[4]}$. Endobronchial tumors are rare in children, accounting for only $0.2 \%$ of all pediatric malignancies ${ }^{[3]}$. In a large historical series of extranodal non-Hodgkin lymphoma, only $3.6 \%$ presented with involvement of the pulmonary parenchyma or tracheobronchial tree as the primary site of disease $\mathrm{e}^{[5]}$. In our unit, this is the only case reported over a screening of 30 patients treated for thoracic malignancy. 
Rani Kanthan et al. reported an exhaustive list of pediatric endobronchial ALCLs represented by 7 cases of pediatric endobronchial primary anaplastic large cell lymphoma. Among them, only 4 presented localized disease like our patient ${ }^{[2,6-8]}$.

According to Neville et al, among 160 patients less than 20 years old, affected by malignant pediatric lung neoplasms, the most common primary bronchial tumor in childhood is carcinoid tumor $(51.6 \%)$, followed by sarcoma $(11 \%)$ and mucoepidermoid carcinoma $(9 \%)^{[3]}$. Lymphoma rarely presents as an endobronchial lesion and is usually associated with advanced widely disseminated disease ${ }^{[1]}$. In non-Hodgkin's lymphoma, endobronchial lesions are often seen in the main bronchi followed by the lobar bronchi and the trachea. The most common mechanism involves direct bronchial invasion and lymphatic spread ${ }^{[9]}$.

The principal symptoms of the disease are frequently non-specific, with dyspnea, cough and wheeze, followed by hemoptysis. These complaints could mimic a partially refractory asthma in some cases. Thus, pediatricians should evocate bronchial tumor in case of failure to respond to bronchodilator treatment $^{[10]}$.

Chest radiography shows lung collapse in approximately half of the cases with endobronchial involvement ${ }^{[11]}$ and a mass or hilar shadow in $20 \%$ of cases. In our patient, lung collapse was suspected on the base of the chest X- ray and US results. In patient presenting with an opaque hemithorax, mediatinum position is an important sign to mention. A mediatinum shift to the opposite side of the opaque hemithorax may suggest the presence of an abundant pleural effusion, while a shit to the same side, commonly described as a retraction, is generally related to a pulmonary atelectasis. Considering the same logic, an opaque hemithorax with no médiastinal shift may suggest the association of an atelectasis with a pleural effusion.

It is difficult clinically and radiologically to distinguish between endobronchial adenoma, carcinoma or lymphoma. Though, fibre-optic bronchoscopy with biopsy remains the definitive and the predominate investigation. Such distinction is extremely important, as the primary treatment of a malignant endobronchial tumor is surgical, whereas, in lymphoma, chemotherapy remains the gold standard.

Treatment of endobronchial ALCL depends on the extent of the disease. Primary lymphoma arising from the bronchus is usually a chemotherapy sensitive tumor.

Prognosis of patients with isolated endobronchial lymphoma like our patient is not worse than prognosis of other local presentations of lymphoma. The median survival in patients with localized disease is 3 years compared to 13 months in those with generalized disease ${ }^{[1]}$.

ALCL in children responds well to chemotherapy, with complete remission in themajority of cases. Our patient, showed a quick and deep improvement in her clinical situation after only one course of chemotherapy. 2 years follow-up, concluded to a complete remission without any evidence of tumor recurrence. The most significant prognostic factor for children with ALCL is ALK positivity ${ }^{[2]}$, which is associated with a good therapeutic response and longer overall survival $(79.8 \%$ for ALK positive disease versus $32.9 \%$ for ALK negative disease for 5-year overall survival) $)^{[2]}$.

Because of the rarity of this tumor, guidelines for management are not clear and the optimal therapy still remains to be determined.

\section{Conclusion}

Malignant lymphoma arising from endobronchial lesions is extremely rare and represents only $0.4 \%$ of all lymphomas. It is rarely seen as a primary endobronchial exclusive location. Bronchial ALCL must be considered in the differential diagnosis in case of airway obstruction as especially in young patients. Histopathology is the most efficient tool to differentiate ALCL from other benign and malignant endobronchial lesions. It is very important to establish the diagnosis of a lymphoma in front of endobronchial tumor since appropriate treatment can lead to a total remission.

Conflict of Interest: The authors have no conflicts of interest or funding to disclose.

\section{References}

1. Bellah, R.D., Mahboubi, S., Berdon, W.E. Malignant endobronchial lesions of adolescence. (1992) PediatrRadiol 22(8): 563-567.

Pubmed|Crossref|Others

2. Rani, K., Jenna-Lynn, S., Grant, M. Isolated pediatric endobronchial primary anaplastic large cell lymphoma. (2014) J PedSurg Case Reports 2(2): 66-69

Pubmed | Crossref $\mid$ Others

3. Neville, H.L., Hogan, A.R., Zhuge, Y., et al. Incidence and outcomes of malignant pediatric lung neoplasms. (2009) J Surg Res 156(2): 224230.

Pubmed | Crossref| Others

4. Dawe, C.J., Woolner, L.B., Parkhill, E.M., et al. Cytological studies of sputum secretions and serous fluids in malignant lymphoma. (1955) Am J Clin Pathol 25(5): 480-488.

Pubmed |Crossref $\mid$ Others

5. Freeman, C., Berg, J.W., Culter, S.J. Occurrence and prognosis of extranodal lymphomas. (1972) Cancer 29(1): 252-260.

Pubmed | Crossref | Others

6. Pavlov, N., Pavlov, V., Culic, S., et al. Endobronchial ALK+ anaplastic large-cell lymphoma resembling asthma in a 13-year-old girl. (2013) J Pediatr Hematol Oncol 35(1): 4-6.

Pubmed | Crossref|Others

7. Guerra, J., Eschevarria-Escudero, M., Barrios, N., et al. Primary endobronchial anaplastic large cell lymphoma in a pediatric patient. (2006) PR Health Sci J 25(2):159-161.

Pubmed | Crossref $\mid$ Others

8. Bhalla, R., Mc Clure, S. Pathologic quiz case: a 17-year-old adolescent girl with a short history of dyspnea, Endobronchial, anaplastic large cell lymphoma, T-cell phenotype. (2003) Arch Pathol Lab Med 127(12): 430-431.

Pubmed |Crossref $\mid$ Others

9. Kilgore, T.L., Chasen, M.H. Endobronchial non-Hodgkin's lymphoma. (1983) Chest 84(1): 58-61.

Pubmed |Crossref | Others

10. Khodadad, K., Karimi, S., Arab, M., et al. Primary anaplastic large cell lymphoma of trachea with subcutaneous emphysema and progressive dyspnea. (2011) Hematol Oncol Stem Cell Ther 4(4): 188-191.

Pubmed | Crossref| Others

11. Eng, J., Sabanathan, S. Endobronchial non-Hodgkin's lymphoma. (1993) J Cardiovasc Surg 34(4): 351-354.

Pubmed | Crossref $\mid$ Others 